\title{
Neutronic Performance of a Compact 10 MWe Nuclear Reactor with Low Enrichment $\left(\mathrm{Th}_{x} \mathrm{U}_{1-x}\right) \mathrm{N}$ Fuel
}

\author{
S.S. PARKER @,$^{1,3}$ S. NEWMAN, ${ }^{2}$ and A.J. FALLGREN ${ }^{2}$ \\ 1.-Materials Science and Technology Division, Los Alamos National Laboratory, P.O. Box 1663, \\ SM-30, Bikini Atoll Road, Los Alamos, NM 87545, USA. 2.-Nuclear Engineering and Non- \\ Proliferation Division, Los Alamos National Laboratory, Los Alamos, NM, USA. \\ 3.-e-mail: sparker@lanl.gov
}

\begin{abstract}
Recent interest in compact nuclear reactors for applications in space or in remote locations drives innovation in nuclear fuel design, especially non-oxide ceramic nuclear fuels. This work details neutronic modeling designed to support the development of a new nuclear fuel concept based on a mixture of thorium and uranium nitride. A Monte Carlo N-Particle Version 6.2 (MCNP-6) model of a compact 10 MWe reactor design which incorporates $\left(\mathrm{Th}_{x} \mathrm{U}_{1-x}\right) \mathrm{N}$ fuel is presented. In this context, a "compact" reactor is a completely assembled reactor which may be emptied of coolant and transported by specialized commercial vehicle, deployed by a C130J aircraft, or launched into space. Core geometry, reflector barrels, and the heat exchange zones are designed to support reduction of overall reactor volume of core components while maintaining criticality with a fixed total fuel mass of $4500 \mathrm{~kg}$. Dense mixed nitrides of thorium nitride (ThN) additions in uranium nitride (UN) in 5 wt.\% increments between $0.05 \leq x \leq 0.5$ have been considered for calculation of $k_{\infty}$ and $k_{\text {effective }}$. ThN additions in UN results in a slight increase in the magnitude of the temperature coefficient of reactivity, which is negative by design. The isotopic distribution of the principal actinide inventory as a function of burnup, time, and initial fuel composition is presented and discussed within the context of the proliferation risk of this core design.
\end{abstract}

\section{INTRODUCTION}

Energy abundance in remote locations could enable a broad mission space, yet such technologies require significant investment and development. The evident need for safe, reliable, and affordable high energy density systems exceeds the capability of available technology. In space applications, solar panels and radioisotope thermoelectric generators (RTG) are utilized to generate $<1 \mathrm{~kW}$ of power for a limited period of time before material degradation or source decay renders the power production below that of the operational requirements of the mission. ${ }^{1}$ In remote terrestrial applications, diesel generators are most commonly used to provide power suitable for the function of remote forward operating bases or research stations; while terrestrial

(Received May 22, 2021; accepted August 31, 2021;

published online October 12, 2021) operations allow resupply, constant supply of fuel is expensive, and maintenance of supply lines may place personnel at risk in the case of numerous military applications. ${ }^{2}$ Nuclear power has historically been utilized on naval craft as a means of high energy production for long periods of time, but such reactor designs are not made for portability nor may they operate in a mode of reliable self-regulation. No available portable technologies exist which allow significant power production $(>10 \mathrm{MWe}$ ) for long operating times (10-15 years). ${ }^{3}$ Very small, compact nuclear reactors can readily address the needs of power production in remote locations, and could support applications which are typically powerlimited.

Low-power compact nuclear reactors $(<10 \mathrm{kWe})$ have been manufactured and utilized for application in space. The first disclosed use of a nuclear fission power system in space was a $0.5-\mathrm{kWe}$ Systems for Nuclear Auxillary Power (SNAP-10A) satellite 
launched by the United States in 1965 . The SNAP program was then adapted to support the Apollo missions. Around this time frame the USSR began the Radar Ocean Reconnaissance Satellite (RORSAT) program, in which over 31 nuclear-powered Kosmos satellites were launched between 1965 and 1987. The Kosmos satellites utilized a fast spectrum BES-5 reactor, which produced $2 \mathrm{kWe}$. Two additional, higher power ( $5 \mathrm{kWe}$ ) TOPAZ satellites were also launched as part of the RORSAT program. Given the enormous costs associated with payload mass, all the designs used in the SNAP and RORSAT programs were highly enriched ( $>90 \%$ ${ }^{235} \mathrm{U}$ ) fast reactors, which considerably reduced the mass of both the fuel and the coolant compared with thermal reactors of equal power output. These missions may be viewed as successful demonstrations of the feasibility of fission power in space, and programs like the Space Reactor Prototype (SP-100) and the Safe Affordable Fission Engine (SAFE) at NASA continued the research and development into the potential application of fission reactors for space propulsion. ${ }^{4}$

Transportable compact reactors for use in terrestrial applications could serve numerous roles. Recent reports from the Defense Science Board strongly advocate for the development of compact nuclear reactors for use in military applications, disaster relief, and in remote locations. ${ }^{2,5}$ In a comprehensive survey of all available energy systems, a task force on Energy Systems for Forward/Remote Operating Bases concluded that it was in the best interest of the Department of Defense (DOD) to invest in compact nuclear reactor technology in order to provide for current and growing future energy needs; this assessment was based on operational requirements, transportability, automatic or passive operation, safety, and proliferation risk associated with compact reactors in comparison to other energy production systems. ${ }^{2,6-8}$ While compact reactors may readily serve existing needs, the energy requirements associated with projecting US military capability is expected to increase in the coming decades. ${ }^{5}$

This work details neutronic modeling designed to support the development of compact, transportable reactors using a new nuclear fuel concept based on a mixed thorium and uranium nitride fuel. The MegaPower reactor concept under development by Los Alamos National Laboratory (Patent No. US 20160027536 A1) represents an early stage design iteration aimed toward high energy output, transportable, compact nuclear reactors. This compact reactor design is intended to be transportable in a cargo container on a semi-trailer truck, and may be rapidly deployed or removed. ${ }^{9}$ In the event of complete loss of coolant, the reactor will automatically shut down and will dissipate heat to the surrounding air. This reactor utilizes a fast neutron spectrum with low uranium enrichment $(<20$ at.\% ${ }^{235} \mathrm{U}$ ). In comparison to water, the use of liquid salts for the heat transfer fluid allows miniaturization of the heat transfer system. Reflector drums and control rods are used to control the reactivity of the system. The armored, shielded cask doubles as a neutron reflector, which effectively shields any personnel from receiving a neutron dose. The core is designed to operate on a single fuel charge for over a decade, which eliminates the need for fuel shuffling. The strong negative temperature coefficient of reactivity contributes to the inherent safety of this design, and allows for the reactor to operate in a semi-load-following operation. In the event of complete loss of coolant to the core, the reactor automatically shuts down and passively radiates decay heat to the surrounding atmosphere. The choice of materials and the hexagonal geometry of the bundles results in a more homogeneous thermal profile and an even burnup of the fuel. The properties of the fuel strongly influence the potential power level, operating time, safety profile, and the proliferation risk of the reactor. Keeping in mind the initial requirement of compact nuclear reactors (i.e., transportability, safety, self-regulation, long operating life, and $\sim 10 \mathrm{MWe}$ power output), the fuel composition can be tailored to optimize the reactor performance.

Part of the operational flexibility of this reactor design can be attributed to the mixed thorium and uranium nitride fuel. This choice of material is motivated, in part, by the higher actinide density and significantly improved thermophysical properties compared with reference oxide and carbide fuels. ${ }^{10-17}$ In comparison to oxide or mixed oxide fuels, non-oxide ceramic fuels (i.e., carbides, nitrides, silicides) have marginally lower melting points but significantly higher thermal conductivity. ${ }^{11-13}$ In particular, ThN and UN have favorable thermophysical properties for reactor applications and the properties and applications of mixtures of this material are the subject of ongoing research. ${ }^{11,14,18}$ For the case of fixed linear power density from fission across the fuel and for the same period of fuel burnup, the increase in thermal conductivity associated with switching from oxide to nitride fuels results in reduced centerline temperatures and a reduction in the thermal gradients. Nitride fuels, which retain higher thermal conductivity as a function of burnup, exhibit less pronounced temperature-dependent degradation by fuel swelling, grain growth, and fission gas release. ${ }^{15,19}$ Research on the synthesis, fabrication, and characterization of UN and PuN has advanced significantly in recent years. $\mathrm{UN}$ and $\left(\mathrm{U}_{x} \mathrm{Pu}_{1-x}\right) \mathrm{N}$ fuels have been synthesized for characterization, with emphasis on tailoring the initial materials properties for application in gas-cooled fast reactors (GFR), sodium-cooled fast reactors (BN-1200), leadcooled fast reactors (BREST), seed-and-blanket transuranic (S\&B) burner concepts, space propulsion systems for the SP-100 program, and various light water reactor concepts. ${ }^{20-26}$ The varied requirements of these designs necessitate a 
comprehensive view of the materials properties of nitride fuel forms. The thermal and mechanical properties of UN and, to a limited extent, $\left(\mathrm{U}_{x} \mathrm{Pu}_{1-x}\right) \mathrm{N}$, have been measured as a function of temperature and pressure. ${ }^{15,27-29} \mathrm{~A}$ comprehensive summary of these material properties is presented in, ${ }^{29}$ and is used as a key reference for point of comparison. Irradiation testing of UN and mixed $\mathrm{UN}$ and $\mathrm{PuN}$ has been carried out over the past few decades. The thermoconductivity of UN has been determined as a function of fission damage, and volumetric swelling as a function of burnup has been determined up to $3 \%$ and modeled, with reasonable extrapolation, to end-of-service life. ${ }^{30-32}$ Interestingly, fission-induced swelling only appears after $3 \%$ burnup ${ }^{15,33}$ comparative irradiation experiments indicate that fission gas swelling of nitride fuels is significantly lower than that of the carbide. ${ }^{18}$ While the irradiation data on $\mathrm{UN}$ and $\mathrm{PuN}$ is not comprehensive, modeling the initial finding will guide future prototype and commercial-scale applications of nitride fuels. The data needs for $\mathrm{ThN}$ are considerable, given the 25-year lag in the development cycle compared with the other actinide nitride fuel candidates. Recent findings suggest that the favorable thermal properties of ThN lend readily to mixtures of UN and, potentially, UN/PuN. ${ }^{34}$

This work details advanced neutronic modeling of the neutronic performance of $\left(\mathrm{Th}_{x} \mathrm{U}_{1-x}\right) \mathrm{N}$ from $0.05 \leq x \leq 0.5$ within the framework of both an infinite reactor and in the specific application of a modified-MegaPower core design. These models operate with a fast neutron spectrum. An infinite reactor model, while a simplification of the true neutronic environment, is very useful for motivating a discussion of the neutron multiplication properties of $\left(\mathrm{Th}_{x} \mathrm{U}_{1-x}\right) \mathrm{N}$ as a function of $\mathrm{ThN}$ addition in a UN matrix. This model indicates the maximum thorium content for a given enrichment of ${ }^{235} \mathrm{U}$ or ${ }^{233} \mathrm{U}$ in ${ }^{238} \mathrm{U}$. While highly enriched uranium enables favorable design aspects concerning the size reduction of the core, it is practical to limit the uranium enrichment to 'low enriched' so as to simplify security concerns related to the manufacture of the fuel. In the Results and Discussion that follow, the uranium enrichment is fixed at 19.5 at.\%. In order to accommodate low enrichment, it is assumed that all nitrogen in the nitride fuel is enriched to ${ }^{15} \mathrm{~N}$, in order to reduce parasitic absorption. ${ }^{35}$ This assumption may be relaxed if higher enrichments are used. The output of the modifiedMegaPower core model outlines the maximum reasonable operating time of a single charge of fuel as a function of initial fuel composition, while also tracking the populations of all isotopes consumed or produced by fission. Such a result allows a discussion on the potential proliferation risk the $\left(\mathrm{Th}_{x} \mathrm{U}_{1-x}\right) \mathrm{N}$ fuel and waste present. Neutronic modeling was accomplished through Monte Carlo NParticle Version 6.2.

\section{NEUTRONIC MODELING OF REACTIVITY AND BURNUP}

\section{Boundary Condition: $\boldsymbol{k}_{\infty}$}

Reactor models of infinite dimension are used to determine $k_{\infty}$, which is the ratio of the number of neutrons in successive generations. Calculations of this parameter are a useful starting point given that the computational resources needed are minimal. Thus, the geometry and composition of the model can be quickly adjusted before committing significant resources to higher fidelity models. Calculation of $k_{\infty}$ serves as an approximate measure of the neutron economy in a simplified model. The effect of neutron leakage and core size associated with a finite reactor are discussed in " $\mathrm{K}_{\mathrm{eff}}$ " section. $k_{\infty}$ has been determined as a function of thorium addition. The cross section of the infinite reactor is shown in Fig. 1. Magenta regions are the inner ring of fuel pins, the blue regions are the outer ring of fuel pins, the white regions are heat pipes which carry coolant, the yellow region is aluminum nitride, and the green bars are moderators comprised of yttrium hydride. The inner and outer fuel rings are identified separately in order to consider differences in burnup as a function of location in the core. Different structural material, such as HT-9 steel, is being considered in place of aluminum nitride; however, substitution of this material has minimal impact on the calculated multiplication factors. In this model, there is assumed to be no gap between the fuel and the clad (zircaloy) or the surrounding structural framework (aluminum nitride).

For this model, $k_{\infty}$ is plotted as a function of atom fraction of thorium in $\left(\mathrm{Th}_{x} \mathrm{U}_{1-x}\right) \mathrm{N}$ in increments of 5

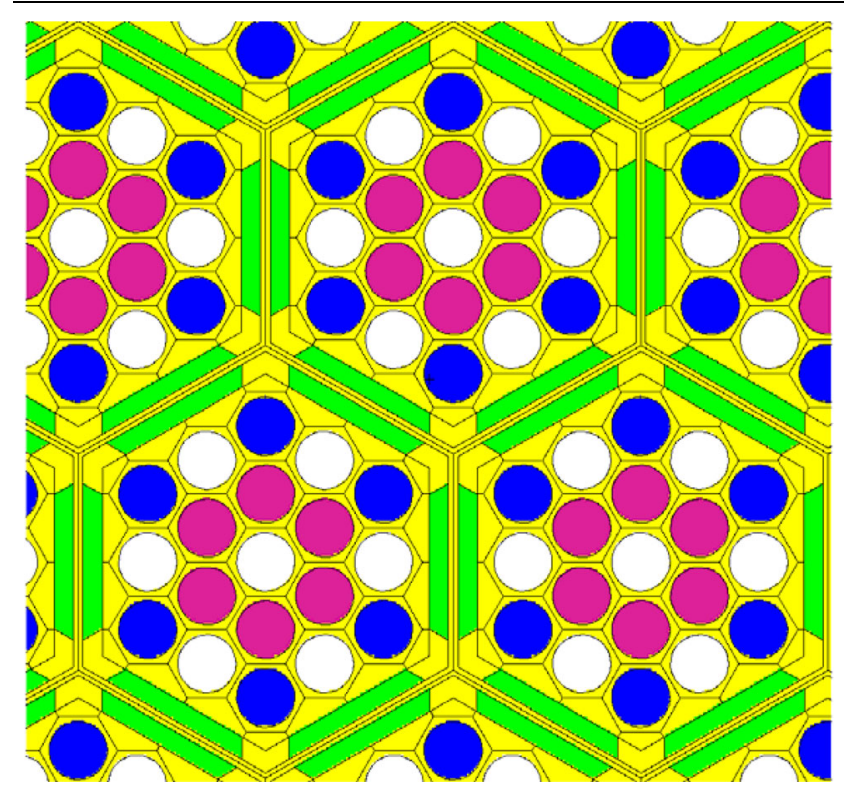

Fig. 1. Shown is a cross-section of an infinite arrangement of fuel bundles. The blue and magenta regions correspond to the outer and inner fuel positions, respectively. The white regions are heat pipes. The yellow region is aluminum nitride (or stainless steel), and the green bars are moderators made of yttrium hydride. 
at. $\%$, from 0 at. $\%$ to 70 at.\%, in Fig. 2 . The $\mathrm{k}_{\infty}$ of UN fuel in this configuration is 1.38 (supercritical). Incremental additions of $\mathrm{ThN}$ result in a linear decrease in the multiplication factor until a maximum concentration of $\mathrm{ThN}$ is reached at 58 at.\%. In reality, given neutron leakage and the anticipated decrease of reactivity with time, thorium should be limited to lower quantities than this limit. The ultimate upper limit of thorium will be set by burnup calculations, given the design requirements of how long the core should operate at a given power level. The interesting conclusion drawn from this observed relationship between $\mathrm{k}_{\infty}$ and thorium content is the apparent insensitivity of such additions. However, this should not be surprising, since one non-fissile isotope $\left({ }^{238} \mathrm{U}\right)$ is being replaced by another $\left({ }^{232} \mathrm{Th}\right)$.

\section{$\boldsymbol{K}_{\text {eff }}$}

While ${ }_{90}^{232} T h$ is not fissile, a series of neutron absorptions starting with ${ }_{90}^{232} T h$ will produce ${ }_{92}^{233} U$ and ${ }_{92}^{234} U$, which are fissile and fissionable, respectively. Initially, neutron absorptions by ${ }_{90}^{232} \mathrm{Th}$ are parasitic and act to reduce $k_{\infty}$. This is useful, given that the system must be supercritical and downregulated by controlling neutron leakage or by parasitic absorption in burnable poisons. As fuel burnup accumulates, the fissile and fissionable isotopes produced by ${ }_{90}^{232} T h$ contribute to neutron generation by introduction of $v\left({ }_{92}^{233} U\right) \cdot \Sigma_{F}$ and $v\left({ }_{92}^{234} U\right) \cdot \Sigma_{F}$. While not desirable from a non-proliferation stand point, a small contribution from plutonium isotopes $\left[v\left({ }_{94}^{239} P u\right) \cdot \Sigma_{F}\right.$ and $\left.v\left({ }_{94}^{240} P u\right) \cdot \Sigma_{F}\right]$ generated from absorption on ${ }_{92}^{238} U$ will also increase neutron generation. One of the practical consequences of additions of $\mathrm{ThN}$ in UN is that it minimizes the reduction of $\mathrm{k}_{\infty}$ over the lifecycle of the reactor. The cross section and scaled representations of the finite reactor model used for determination of K-effective $\left(k_{\text {eff }}\right)$ as a function of burnup and of initial thorium addition are shown in Fig. 3. For scale, the design shown is intended to fit within a standard shipping container. The reflector drums sit within a shielding matrix of low $\mathrm{Z}$ material in order to protect operators. The heat exchange system and turbine are not shown. Reflectors are shown in the shutdown orientation, and may rotate up to 180 degrees to reduce neutron leakage.

The reactor can be shut down with control rods or with the reflector drums. $k_{\text {eff }}$ as a function of time is plotted in Fig. 4 for 5 at.\% incremental additions of ThN in $\left(\mathrm{Th}_{x} \mathrm{U}_{1-x}\right) \mathrm{N}$ from $0.05 \leq x \leq 0.5$ in the case of continuous operation at a power level of $10 \mathrm{MWe}$. The observed decrease in $\mathrm{k}_{\text {eff }}$, especially at startup, is shown in calculations of $k_{\infty}$ in Fig. 2. The percent reduction in $\mathrm{k}_{\text {eff }}$ as a function of thorium content at 8 years is less than the effect at startup due to accumulation of ${ }_{92}^{233} U$ and ${ }_{92}^{234} U$ from neutron capture on ${ }_{90}^{232} \mathrm{Th}$. Indeed, the slope of $\mathrm{k}_{\text {eff }}$ vs time is reduced by $14.7 \%$ from the most dilute composition $(x=0.05)$ to $(x=0.25)$. The benefit of a more uniform neutron multiplicity over time is that less burnable poisons are required in the initial fuel charge. While thorium additions up to $(x=0.50)$ are possible, the composition $\left(\mathrm{Th}_{0.25} \mathrm{U}_{0.75}\right) \mathrm{N}$ was chosen as a reasonable balance between the resultant thermal and mechanical properties of the mixture, published in parallel with this modeling work, while still retaining sufficient neutron multiplication to remain critical for up to a decade of continuous operation at $10 \mathrm{MWe}$.

\section{Temperature Coefficient of Reactivity}

The temperature coefficient of reactivity, $\alpha_{T}$, is a measure of the reactivity change in response to the

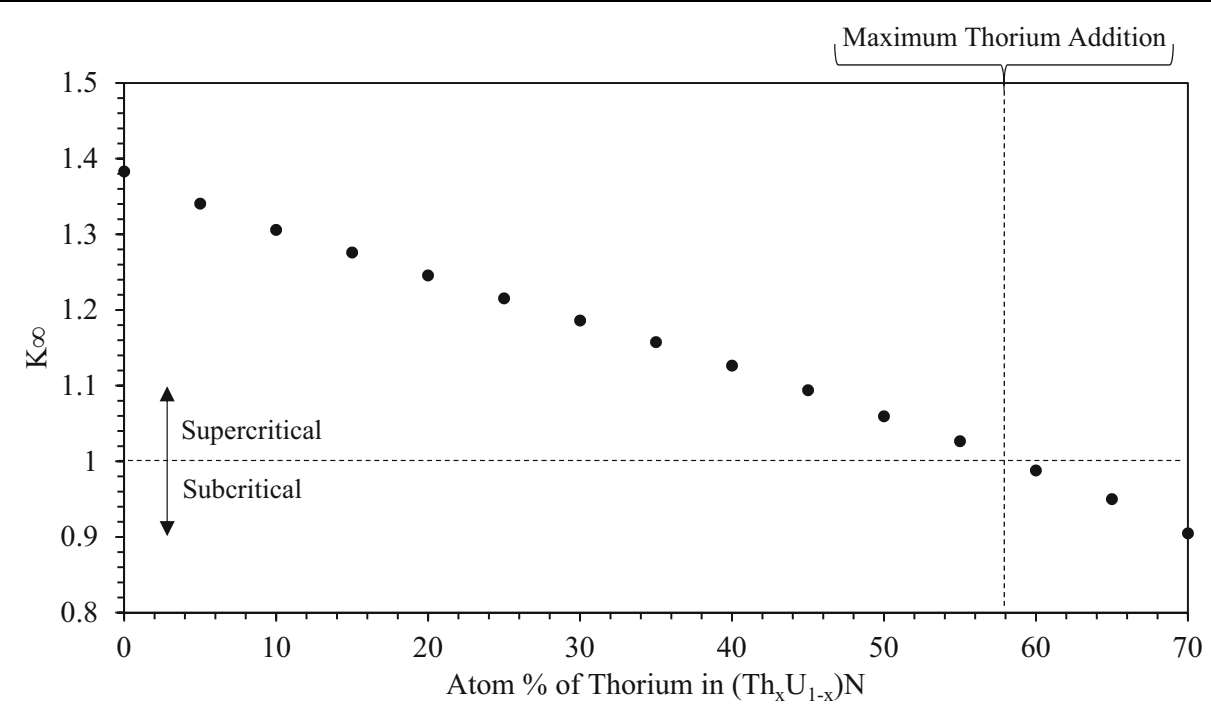

Fig. 2. Shown is a plot of $k_{\infty}$ as a function of at.\% thorium addition in $\left(\operatorname{Th}_{x} \mathrm{U}_{1-x}\right) \mathrm{N}$. These data are simulated from the infinite lattice layout and have been developed for a uranium enrichment of 19.5 at. $\%{ }^{235} \mathrm{U}$ in ${ }^{238} \mathrm{U}$. 


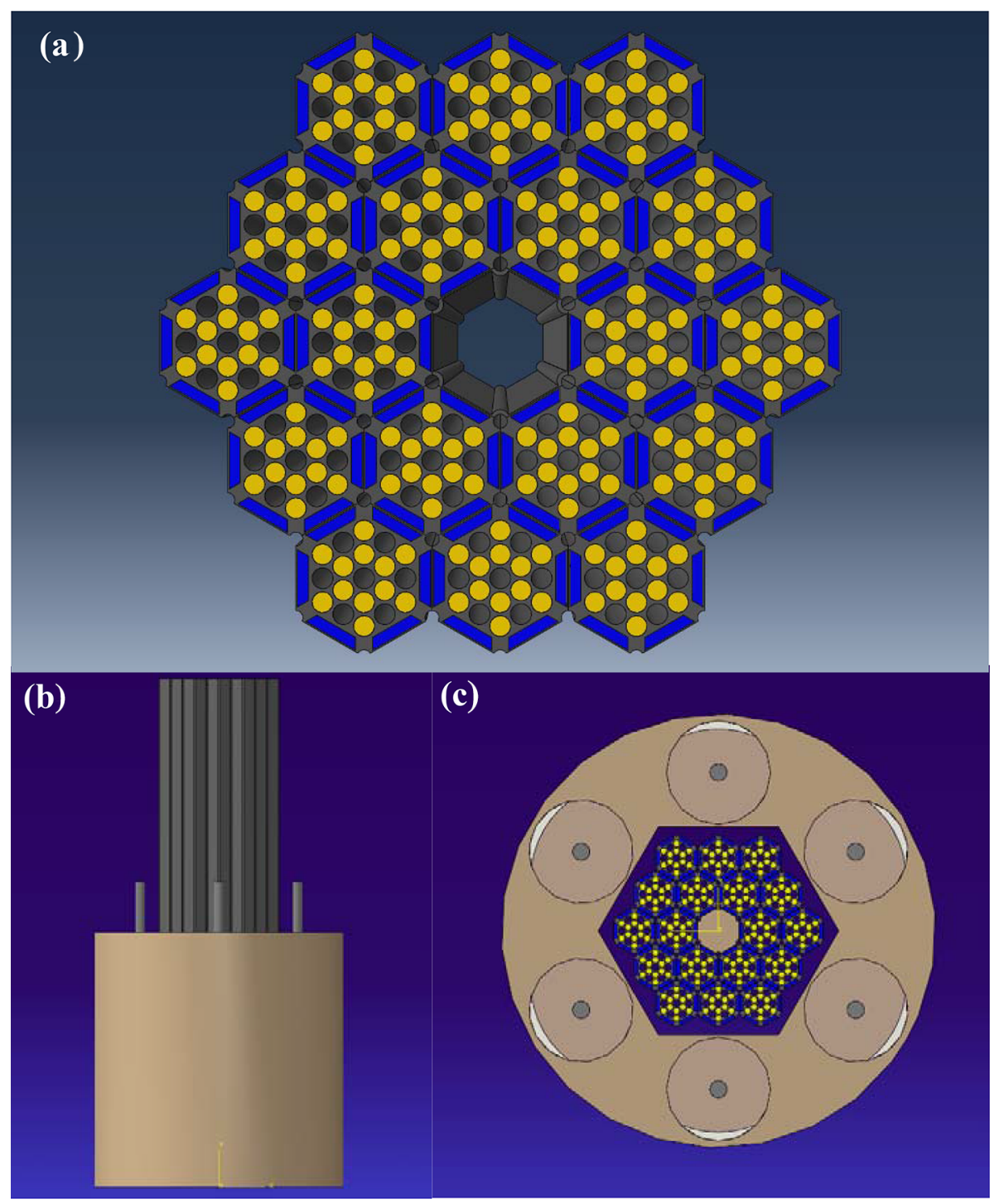

Fig. 3. A scaled representation of the compact reactor model. (a) Scaled finite core cross section. Gold is $\left(\operatorname{Th}_{x} \mathrm{U}_{1-x}\right) \mathrm{N}$, blue is yttrium hydride, and gray is the reactor structural components (modeled as HT9). Open circles are heat pipes. (b) A profile view of the core with the heat exchange pipe protruding on top. (c) A cross section of the core which shows the fuel, heat pipes, deflectors, and shielding. The circular regions in the outer drum represent cylindrical reflector drums. The reactor is depicted in the shutdown state (i.e., reflector drums are facing out).

change in temperature of the reactor. Core reactivity, $\rho(t, T)$, is given by Eq. 1 , and $\alpha_{T}$ is given by Eq. 2:

$$
\begin{gathered}
\rho(t, T)=\Delta k_{\text {effective }} / k_{\text {effective }} \\
\alpha_{T} \equiv \frac{\partial \rho}{\partial T} \cong \frac{1}{k_{\text {effective }}} \cdot \frac{\mathrm{d} k}{\mathrm{~d} T}
\end{gathered}
$$

Changes in core temperature affect neutron multiplication, primarily through changes in resonance absorption in the fuel due to Doppler broadening, and changes to the neutron energy spectrum due to changes in the density of the moderator. The temperature coefficient of reactivity is plotted as a function of temperature in Fig. 5 for all compositions studied.
The temperature coefficient of reactivity is a measure of the inherent safety of the core, and is an essential design parameter of the fuel to assure that increases in reactor power result in a decrease in reactivity on a response time-scale proportional to the change in power. The increase in fuel temperature leads to an increase in resonance absorption, primarily among the fertile isotopes $\left({ }^{238} \mathrm{U},{ }^{240} \mathrm{Pu},{ }^{232} \mathrm{Th},{ }^{234} \mathrm{U}\right)$. However, in a fast reactor the neutron energy spectrum spans the resonance absorption of both fertile and fissile nuclei $\left({ }^{235} \mathrm{U}\right.$, $\left.{ }^{233} \mathrm{U},{ }^{239} \mathrm{Pu},{ }^{241} \mathrm{Pu}\right) . \alpha_{T}$ is plotted in Fig. 5 at the onset of the reactor lifecycle, and so the only dominant contributions are from the initial fertile and fissile materials in the fuel: ${ }^{238} \mathrm{U},{ }^{232} \mathrm{Th}$, and ${ }^{235} \mathrm{U}$. Potential effects of the evolved fertile and fissile nuclei are discussed in the context of fuel 
Neutronic Performance of a Compact 10 MWe Nuclear Reactor with Low Enrichment

$\left(\operatorname{Th}_{x} \mathrm{U}_{1-x}\right) \mathrm{N}$ Fuel

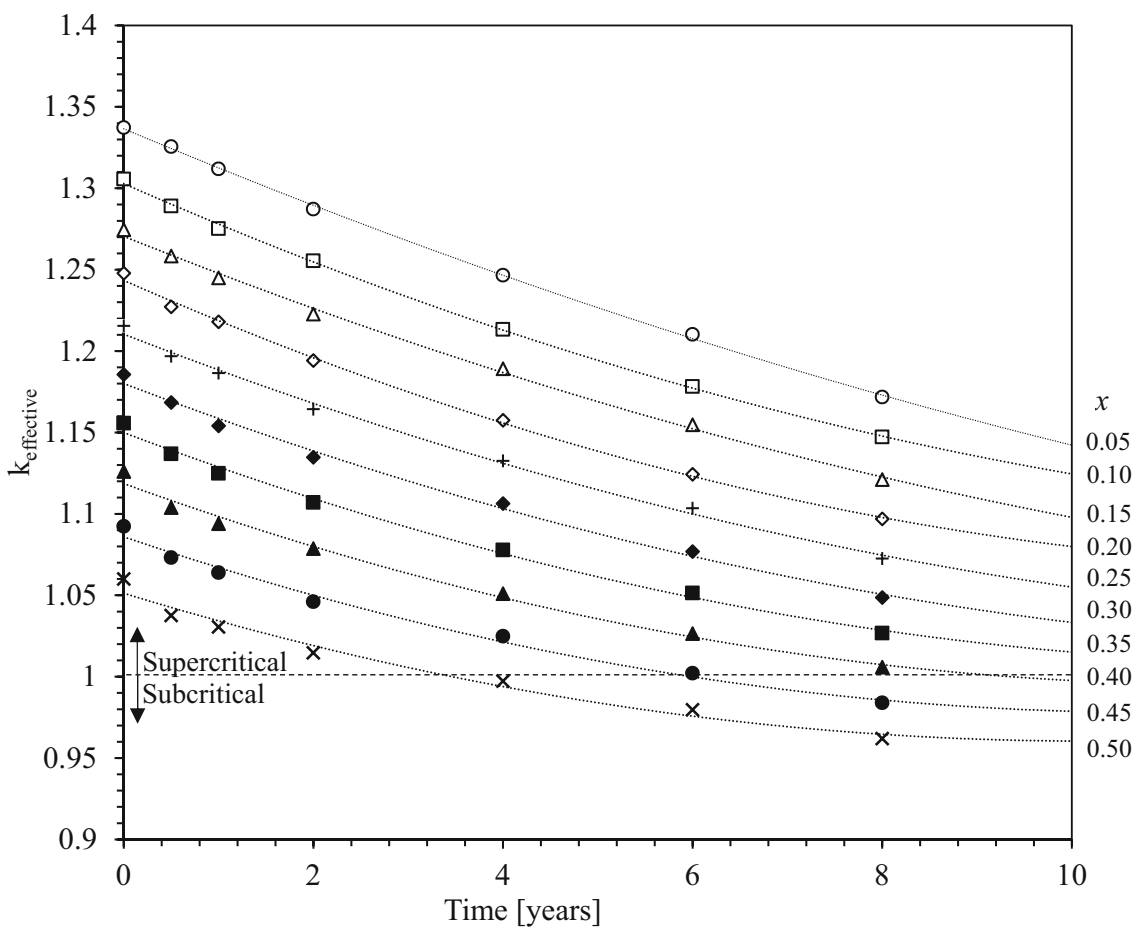

Fig. 4. $k_{\text {eff }}$ vs time, in years, is shown for various fuel compositions. Criticality is marked on the plot as a dashed line. Initial impact of poison buildup from beginning of life is omitted in order to clearly show the impact of changes in the ratio of ThN to UN.

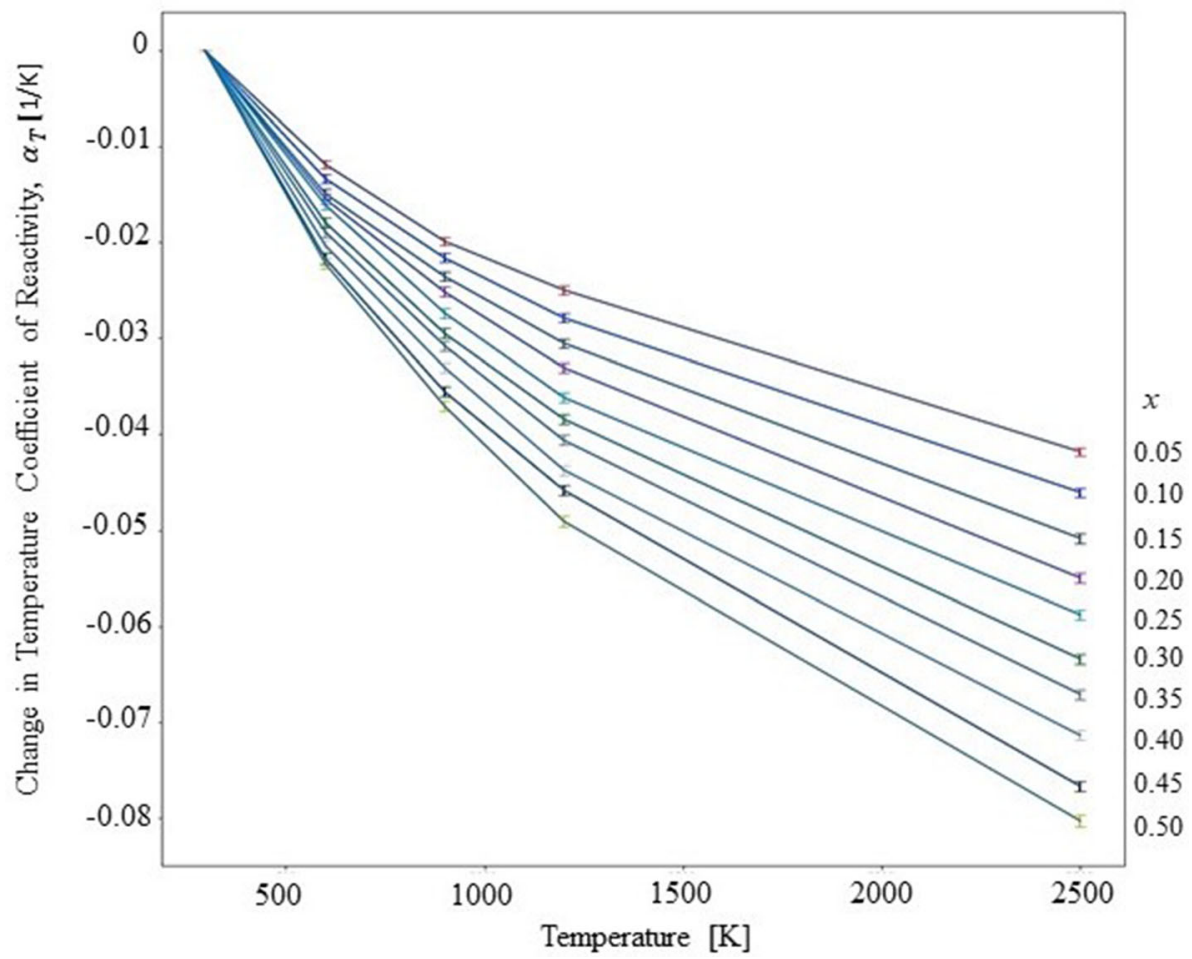

Fig. 5. The change in reactivity per change in temperature of $\left(\operatorname{Th}_{x} U_{1-x}\right) \mathrm{N}$, for values of $x$ between 0.05 and 0.5 for changes in temperature from $500 \mathrm{~K}$. Addition of ThN in UN leads to an increase in Doppler broadening and resonance absorptions in the fuel, which leads to an increase in the magnitude of the negative temperature coefficient of reactivity. Error bars are reported as the calculated standard deviation from MCNP.

breeding in the following sections. It is shown in the figure above that there is an increase in the magnitude of the negative temperature coefficient of reactivity with increasing thorium content, due primarily to an increasingly negative Doppler coefficient. This indicates that the core will have a 
prompt tendency to self-regulate, and allows the reactor to operate in a mode of pseudo load-following. That is to say, increased power demand will extract additional heat from the coolant, which will result in a temperature decrease in the core and cause an increase in reactivity. The opposite will also be true, especially in the event of a rapid core power excursion. Additions of ThN to UN greatly enhances the built-in safety of the fuel, the effect of which increases with increasing temperature of the fuel.

\section{Burnup-Isotopic Distribution of Key Actinide Species}

The population of key isotopes as a function of time and thorium addition was determined. The primary isotopes of concern are the fissile and fertile isotopes, both included in the initial fuel charge and generated by neutron absorptions during normal operation of the reactor. The primary absorption pathways for the breeding of fissile isotope ${ }^{233} \mathrm{U}$ are shown in Fig. 6:

Neutron absorption reactions are denoted $(n, 2 n)$ and $(n, \gamma)$; the cross section of each absorption or fission is dependent on the neutron energy and the temperature of the fuel. While other reaction pathways are possible, those shown in Fig. 6 are the dominant reactions leading to the creation of additional fissile isotopes during reactor operation. While not shown here, ${ }^{237} \mathrm{~Np}$, which is fissionable in a fast neutron spectrum, is produced by successive neutron absorptions on uranium isotopes or by $(n, 2 n)$ reactions on isotopes of plutonium. It is found in this study that less than $800 \mathrm{~g}$ of ${ }^{237} \mathrm{~Np}$ accumulate over a 10-year operating cycle, regardless of the initial nitride mixture utilized. Compared with the rest of the fissile inventory, this quantity of material is sufficiently low so as to be excluded from the discussion of reactor performance. This amount of material is also insufficient for a critical mass, and therefore will not be included in a discussion of the proliferation risk presented by the spent fuel. ${ }^{36}$

This reactor is not designed to be a breeding reactor; the conversion ratio is less than 1 . Rather, the additional fissile material created by transmutation serves to increase $\mathrm{k}_{\text {eff }}$ in the later years of reactor operation ( $>5$ years) and thereby extend the service life of the core. The balance in the

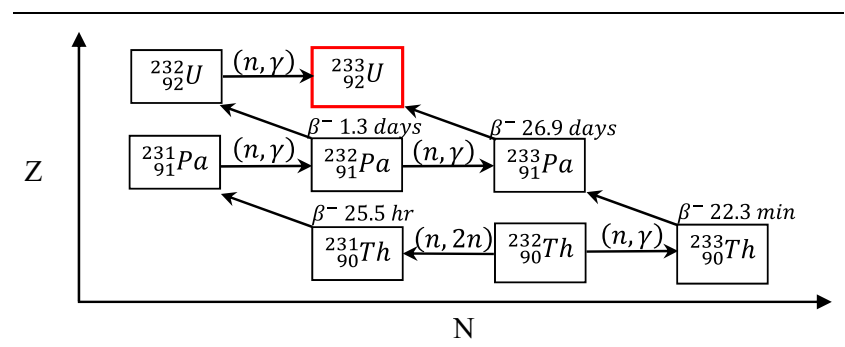

Fig. 6. The reaction pathways for the generation of additional fissile material starting with neutron capture on ${ }^{232} \mathrm{Th}$. Fertile species are marked as red. $\mathrm{Z}$ is the proton number and $\mathrm{N}$ is neutron number. uranium economy as a function of time and initial fuel composition is shown in Fig. 7. In the plot of ${ }^{235} \mathrm{U}$ utilization vs time, the relative consumption of ${ }^{235} \mathrm{U}$ increases with increasing thorium content. In the case of high thorium content $(x=0.5), 61 \%$ of the ${ }^{235} \mathrm{U}$ is used over the life of the reactor, while the minimal thorium loading $(x=0.05)$ only utilizes $43 \%$ of the initial fissile uranium. However, the enrichment of ${ }^{235} \mathrm{U}$ to ${ }^{238} \mathrm{U}$ is fixed at 19.6 at.\%. The high thorium loading design uses $10.6 \mathrm{~kg}$ less of ${ }^{235} \mathrm{U}$ compared with $\left(\mathrm{Th}_{0.05} \mathrm{U}_{0.95}\right) \mathrm{N}$, where $\sim 41 \mathrm{~kg}$ of ${ }^{235} \mathrm{U}$ undergoes fission. Thus, the apparent increase in utilization observed in the plot is due to the fact that ${ }^{235} \mathrm{U}$ is initially being consumed at the same rate in all compositions, but there is less material present in the starting composition with increasing thorium concentration. More interesting is the apparent reduction in slope seen at later years in the ${ }^{235} \mathrm{U}$ utilization curves at all compositions. The reason is that the inventory of ${ }^{233} \mathrm{U}$ created from neutron absorption in ${ }^{232} \mathrm{Th}$ builds considerably over time, and, in the case of $(x=0.5)$, eventually accounts for as much as $34 \%$ of the total quantity of fissile uranium isotopes in the fuel.

In order to discuss the impact of absorption on ${ }^{238} \mathrm{U}$ and the production of minor quantities of plutonium, the total fissile and fertile inventories are plotted in Fig. 8. In the dilute limit of thorium addition, $\sim 5.2$ at. $\%$ of all fertile material, which is nearly all ${ }^{238} \mathrm{U}$, undergoes transmutation. Adding $50 \%$ thorium results in a $2.7 \%$ increase in the total utilization of fertile materials, which indicates that thorium undergoes neutron capture at nearly twice the rate of ${ }^{238} \mathrm{U}$. This was also observed to be the case in the reduction of the slope of the $k_{\text {eff }}$ curve over time. It is interesting to note that the total utilization of fissile species decreases with increasing thorium content. The magnitude of this effect amounts to a nearly $20 \%$ reduction in the utilization of the available fissile material. That is to say, nearly $20 \%$ of additional fissile material is created in years 4-10 in the case of higher thorium loading. Increasing the initial enrichment of ${ }^{235} \mathrm{U}$ would reduce parasitic absorption by ${ }^{238} \mathrm{U}$ and would allow considerably higher thorium concentration. While not included in this study, further modeling of mixed nitrides as a function of higher ${ }^{235} \mathrm{U}$ enrichment $(>20$ at.\%) for higher thorium loading $(0.5 \leq x \leq 0.70)$ could expand the potential design space to allow for extended operation beyond the initial 10-year design requirement.

\section{Proliferation Risk}

The transmutation reactions starting with ${ }^{238} \mathrm{U}$ which lead to the production of plutonium are shown schematically in Fig. 9. ${ }^{241} \mathrm{Pu}$ and ${ }^{242} \mathrm{Pu}$ are produced in negligible amounts, and are not included in the following analysis. Given the compact nature of this reactor design, the total quantity of plutonium isotopes bred by neutron absorption on 

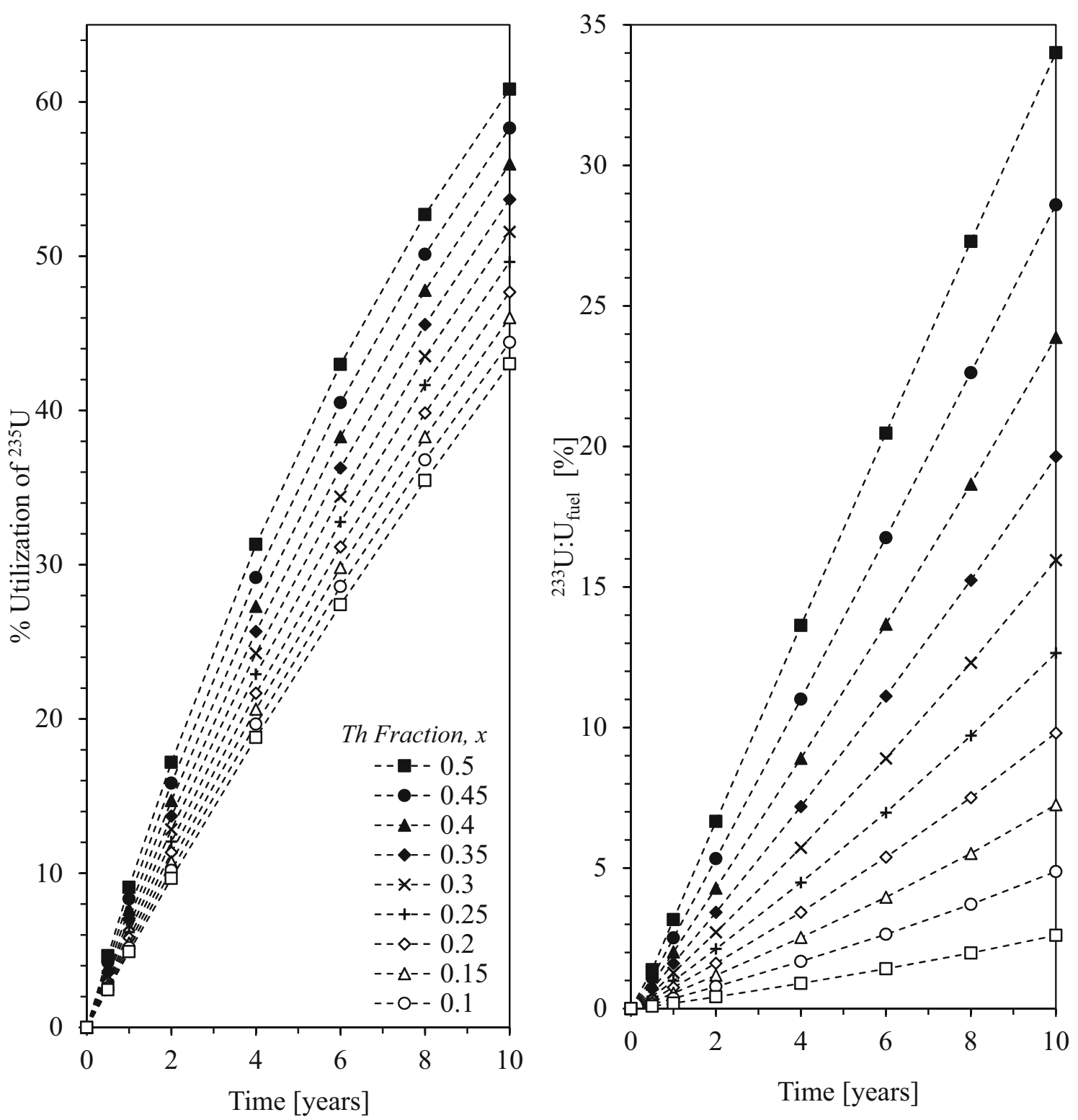

Fig. 7. Left, \% utilization of ${ }^{235} \mathrm{U}$ as a function of time and initial fuel composition; right, ratio of ${ }^{233} \mathrm{U}$ to the total inventory of fissile isotopes of uranium in the fuel. Both plots share a common legend.

${ }^{238} \mathrm{U}$ is relatively small, and this quantity decreases with increasing thorium content. However, the plutonium inventory as a function of time must be understood, as this could be a significant proliferation risk for this core design. Understanding the rate of generation and consumption of plutonium isotopes as a function of time and initial fuel composition will illustrate how the initial fuel composition might be tailored so as to reduce the risk of proliferating special nuclear material (SNM) which could be readily formed into a weapon.

Reactor-grade plutonium is a term coined for the typical isotopic distribution of plutonium found in spent fuel from light water reactors and describes a mixture of primarily ${ }^{239} \mathrm{Pu}$ with at least 19 at.\% ${ }^{240} \mathrm{Pu}$. This definition is applied to large thermal reactors utilized for commercial power production. However, production of plutonium in fast reactors occurs at a reduced rate compared with thermal reactors. ${ }^{37}{ }^{239} \mathrm{Pu}$ can be used for nuclear weapons, and has favorable characteristics compared with uranium-based weapons. The bare sphere critical mass of ${ }^{239} \mathrm{Pu}$ is significantly less than that of ${ }^{235} \mathrm{U}$; indeed, a reflected critical sphere would weigh $\sim 5-6$ $\mathrm{kg}$, and an explosively compressed mass would be considerably smaller. ${ }^{38,39}$ Another key advantage is that plutonium can be readily chemically separated from uranium by PUREX processing. ${ }^{40}$ However, reactor-produced ${ }^{239} \mathrm{Pu}$ is rarely suitable for use in a weapon, since it is generally formed with an appreciable quantity of ${ }^{240} \mathrm{Pu}$. The high rate of spontaneous fission (1030 neutrons/s $\cdot \mathrm{g}$ ) in ${ }^{240} \mathrm{Pu}$ makes it 

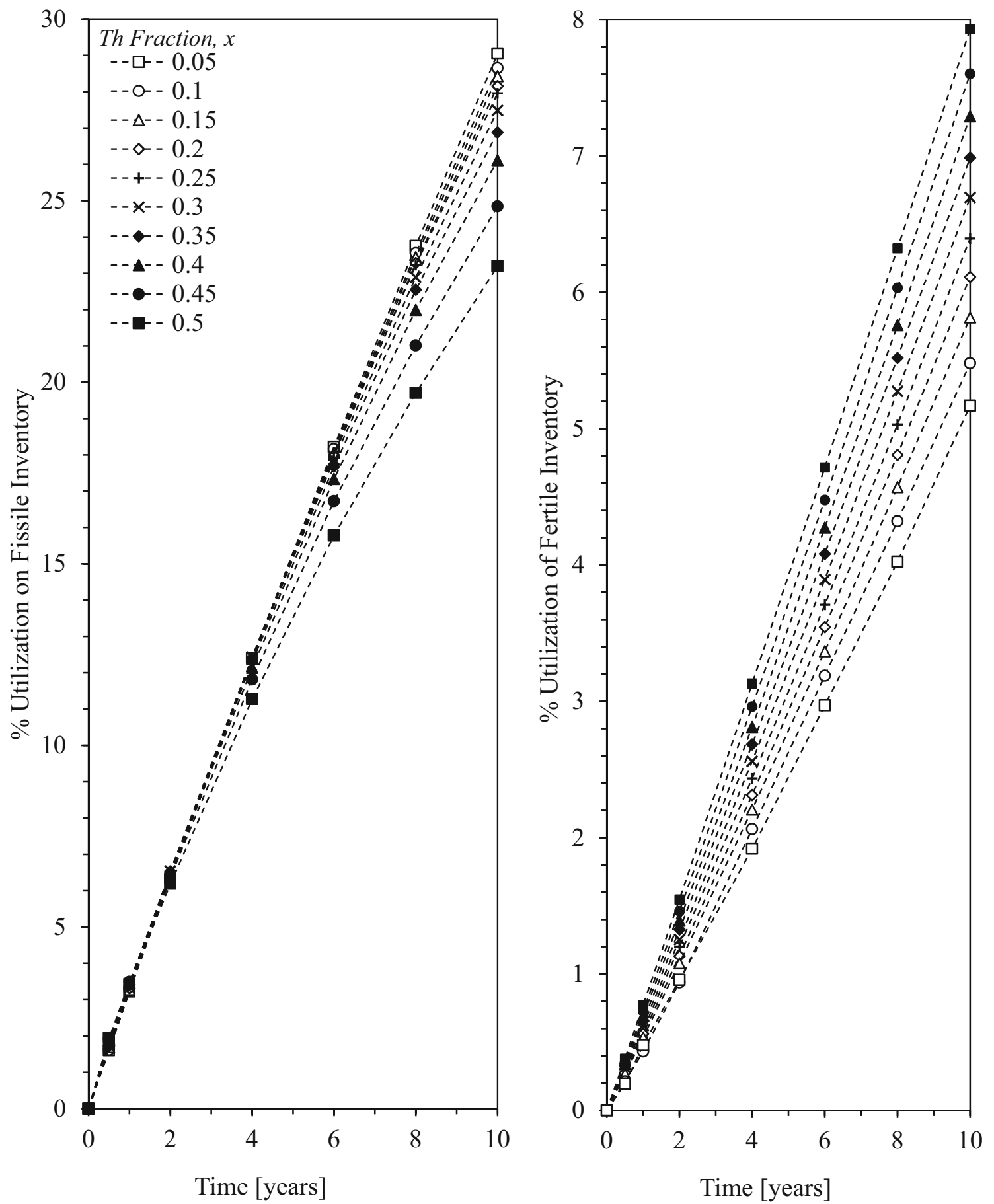

Fig. 8. Left, \% utilization of total fissile inventory. Right, \% utilization of total fertile inventory. The fuel composition is denoted by $x$, which is the initial fraction of thorium to uranium $\left(\mathrm{Th}_{x} \mathrm{U}_{1-x}\right) \mathrm{N}$. Utilization of fissile inventory and fertile inventory are inversely correlated with thorium concentration in the mixed nitride.

unsuitable for use in nuclear weapons, and separation of ${ }^{239} \mathrm{Pu}$ from ${ }^{240} \mathrm{Pu}$ is not practical. ${ }^{41}$ The definition of weapons-grade plutonium allows no more than 6 at.\% ${ }^{240} \mathrm{Pu}$ as an impurity in ${ }^{239} \mathrm{Pu}$. While it is possible to accommodate higher levels of impurities of ${ }^{240} \mathrm{Pu}$, such designs would be very sophisticated, implosion-type devices. ${ }^{42}$ From the perspective of proliferation assessment, it is assumed that countries which have access to such sophistication in nuclear weapon design are not the agents likely to seize a compact nuclear reactor for access to SNM. Rather, it is assumed that theft of this reactor or diversion of the fuel would be perpetrated by states or state sponsored agents 
which do not otherwise have access to these materials through a state sponsored nuclear weapons program.

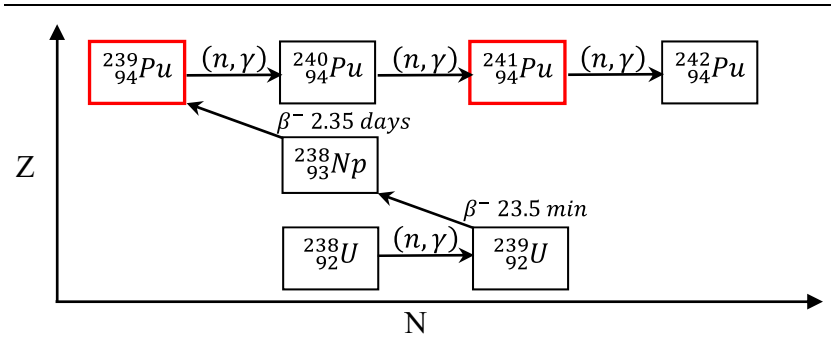

Fig. 9. The reaction pathways for the generation of additional fissile material starting with neutron capture on ${ }^{238} \mathrm{U}$. Fertile species are marked as red. $\mathrm{Z}$ is the proton number and $\mathrm{N}$ is neutron number.
In Fig. 10, the regions of concern of material proliferation are highlighted in red. This region may be eliminated, or reduced by controlling the initial composition of the fuel. Indeed, for sufficiently high thorium content $(0.35 \geq x)$, there is sufficient ${ }^{240} \mathrm{Pu}$ so as to render the plutonium unfavorable for diversion. This is shown by the composition lines in the plot to the right which are in excess of the maximum impurity level before the assumed minimum mass of ${ }^{239} \mathrm{Pu}$ is generated at $\sim$ year 4 . This implies two important results. The first is that if an adversarial state were to pursue mixed nitride fast reactor technology, the initial composition of ${ }^{238} \mathrm{U}$ must be carefully considered in order to anticipate the evolution of plutonium isotopes over time. In the case of manufacture and service of these types of reactors for the DOD, the second result is that the
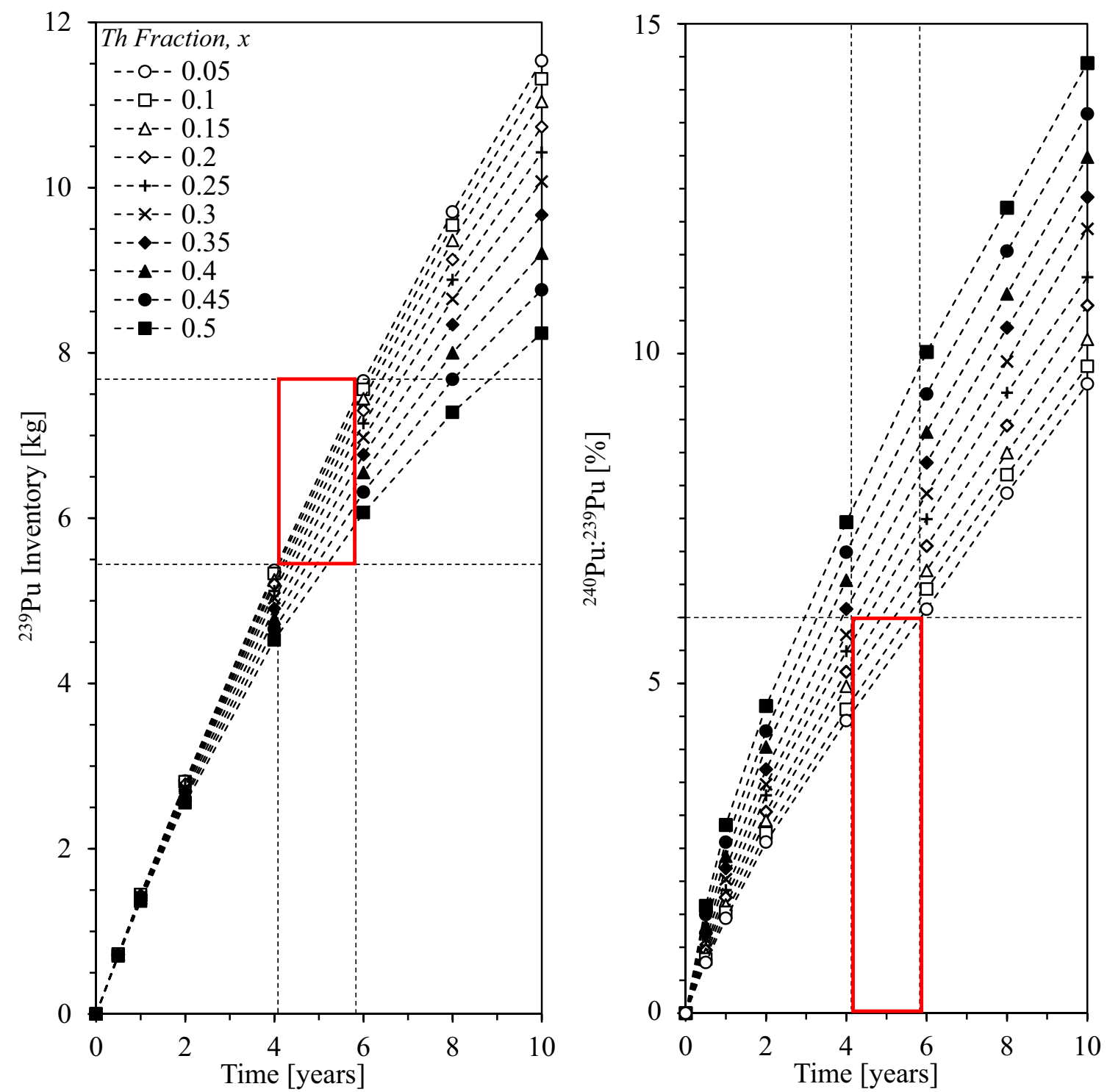

Fig. 10. Inventory of ${ }^{239} \mathrm{Pu}$ (left) and the ratio of ${ }^{240} \mathrm{Pu}:{ }^{239} \mathrm{Pu}$ (right) as a function of time and initial fuel composition. Assuming minimum divertible mass of $\sim 5.4 \mathrm{~kg}$ from bare sphere calculations, and a maximum impurity of 6 at. $\%{ }^{240} \mathrm{Pu}$, regions in time and composition space are highlighted in red so as to illustrate the zone where the fuel is at risk of diversion. 
initial enrichment of ${ }^{235} \mathrm{U}$ and addition of ${ }^{232} \mathrm{Th}$ may be chosen to be sufficiently high that the remaining ${ }^{238} \mathrm{U}$ is too dilute to pose significant risk of transmutation. This is an important result for the development of compact reactors, as it outlines how the initial fuel composition might be modified so as to lower the proliferation risk. While the argument might be made that the remaining ${ }^{235} \mathrm{U}$ or ${ }^{233} \mathrm{U}$ may be sufficient for a nuclear weapon, this would require isotopic separation of ${ }^{232} \mathrm{U},{ }^{233} \mathrm{U}$, ${ }^{235} \mathrm{U},{ }^{236} \mathrm{U}$, and ${ }^{238} \mathrm{U}$ present in the spent nuclear fuel. While this may be technically possible, the severe radioactivity of the decay products of this mixture, such as the $2.6 \mathrm{MeV}$ gamma ray emitted from ${ }^{208} \mathrm{Tl}$, a decay specie from ${ }^{232} \mathrm{U}$, makes reprocessing and separation impractical. ${ }^{43}$ Isotopic separation of ${ }^{235} \mathrm{U}$ from ${ }^{238} \mathrm{U}$ is a mature technology and would be considerably easier to apply, as opposed to attempting to produce parallel methods on such a diverse, highly radioactive mixture.

\section{CONCLUSION}

The neutronic performance of $\left(\mathrm{Th}_{x} \mathrm{U}_{1-x}\right) \mathrm{N}$ from $0.05 \leq x \leq 0.5$ was presented and discussed within the framework of both an infinite reactor and in the specific application of a compact reactor design under development by Los Alamos National Laboratory. $k_{\infty}$ calculations for the infinite core model were determined as a function of atom fraction of thorium in $\left(\mathrm{Th}_{x} \mathrm{U}_{1-x}\right) \mathrm{N}$ in increments of 5 at.\%, from 0 to 70 at.\%. The infinite model remains critical from $0 \leq x \leq 0.58$, which indicates that UN is fairly insensitive to thorium addition. This model assumed an enrichment of ${ }^{235} \mathrm{U}$ to ${ }^{238} \mathrm{U}$ of 19.6 at.\% for all compositions studied. $k_{\text {eff }}$ was determined for the case of a finite reactor as a function of time and of initial thorium addition. Additions of ThN in UN leads to a reduction in the slope of $k_{\text {eff }}$ over the lifecycle of the reactor. A maximum composition of $\left(\mathrm{Th}_{0.35} \mathrm{U}_{0.65}\right) \mathrm{N}$ remains supercritical beyond 10 years at the assumed power level. The service life of the reactor can be extended for higher concentrations of ThN if higher enrichments of ${ }^{235} \mathrm{U}$ are considered. The temperature coefficient of reactivity was found to become increasingly negative as both a function of temperature and of thorium addition to the fuel. This is due to an increasingly negative Doppler broadening coefficient. In an analysis of the isotopic distribution as a function of burnup and initial fuel composition, it was found that the maximum thorium loading resulted in significant creation of ${ }^{233} \mathrm{U}$ by transmutation. As much as $34 \%$ of the fissile uranium inventory was ${ }^{233} \mathrm{U}$ by year 10 . It was found that negligible quantities of ${ }^{237} \mathrm{~Np},{ }^{241} \mathrm{Pu}$, and ${ }^{242} \mathrm{Pu}$ were created at any composition over the time range studied. ${ }^{239} \mathrm{Pu}$ and ${ }^{240} \mathrm{Pu}$ were discussed within the context of proliferation risk. It was determined that there exists a vulnerable window wherein the reactor may be at risk of diversion. This window may be eliminated by setting the initial fuel inventory to contain higher uranium enrichment, or by adding a few atom percent ${ }^{240} \mathrm{Pu}$ to make a mixed $\left(\mathrm{Th}_{x} \mathrm{U}_{1-x}\right) \mathrm{N}$ initial fuel charge. While not included in the scope of this study, plutonium or actinide additions could work favorably in more highly enriched $\left(\mathrm{Th}_{x} \mathrm{U}_{1-x}\right) \mathrm{N}$ fuels for the purpose of actinide burning.

\section{ACKNOWLEDGEMENTS}

This work was supported by the U.S. Department of Energy, Office of Nuclear Energy Fuel Cycle Research and Development program. This work was also supported by the Department of Energy National Nuclear Security Administration under Award Number DENA000097 through the Nuclear Science and Security Consortium.

\section{CONFLICT OF INTEREST}

On behalf of all authors, the corresponding author states that there is no conflict of interest.

\section{OPEN ACCESS}

This article is licensed under a Creative Commons Attribution 4.0 International License, which permits use, sharing, adaptation, distribution and reproduction in any medium or format, as long as you give appropriate credit to the original author(s) and the source, provide a link to the Creative Commons licence, and indicate if changes were made. The images or other third party material in this article are included in the article's Creative Commons licence, unless indicated otherwise in a credit line to the material. If material is not included in the article's Creative Commons licence and your intended use is not permitted by statutory regulation or exceeds the permitted use, you will need to obtain permission directly from the copyright holder. To view a copy of this licence, visit $h$ ttp://creativecommons.org/licenses/by/4.0/.

\section{REFERENCES}

1. J.G. Morse, Science 139 (2560), 1175 (1963).

2. D.S. Eady, S.B. Siegel, R.S. Bell, and S.H. Dicke, AEPI Report \#ADB356341 (2009).

3. V.C. Truscello and H.S. Davis, IEEE Spectrum 21 (12), 58 (1984).

4. D. Buden, 1983-1992. No. INEL/MISC-93085. Idaho National Engineering Lab. (1993).

5. Defense Science Board, Technical Report \#AD1022571 (2016).

6. Department of Defense, Annual Energy Management Report \#3-4DB001 (2015).

7. Department of Defense, Operational Energy Annual Report \#9-45A5F2C (2016).

8. US Government Accountability Office, Report \#GAO-09-300 (2009).

9. B. Wang, https://www.nextbigfuture.com (2017). Accessed 9 Apr 2021.

10. T.R. Govindan Kutty, J. Banerjee, A. Kumar, D. Das, and S.R. Bharadwaj, eds., Green Energy and Technology (London: Springer, 2013).

11. S. Hayes, J. Tomas, and K. Peddicord, J. Nuc. Mater. 359 (12), 17 (1990). 
12. Q. Yin and S.Y. Sergey, Phys. Rev. Lett. 100 (22), 225504 (2008).

13. V.I. Vybyvanets, M.L. Taubin, E.S. Solntseva, I.E. Galev, V.G. Baranov, A.V. Tenishev, and O.V. Khomyakov, At. Energ. 117 (4), (2015).

14. J.P. Gorton, B.S. Collins, A.T. Nelson, and N.R. Brown, Nucl. Eng. Des., 355, 110317 (2019).

15. H. Muta, K. Kurosaki, M. Uno, and S. Yamanaka, J. Mater. Sci. 43, 6429 (2008).

16. M. Valter, Thermal conductivity of uranium mononitride (Linkoping University, 2015).

17. M.B. Schaffer, Energy Pol. 60 (1), 4 (2013).

18. C. Ronchi, M. Campana, M. Coquerelle, and J. van de Laar, Nucl. Sci. Technol. 6, 323 (1984).

19. I.J. Hastings and R.D. MacDonald, J. Nucl. Mater. 126, 177 (1984).

20. K. Minato, M. Akabori, M. Takano, Y. Arai, K. Nakajima, A. Tyoh, and T. Ogawa, J. Nucl. Mater. 320, 18 (2003).

21. V.M. Troyanov, A.F. Grachev, L.M.Zabud'ko, and M.V. Skupov, Atom. Energ. 117(2) (2014).

22. R.D. Syarifah, Z. Su'ud, K. Basar, D. Irwanto, S.C. Pattipawaej, and M. Ilham, Int. J. Res. 42, 214 (2018).

23. R.B. Matthews, K.M. Chidester, C.W. Hoth, R.E. Mason, and R.L. Petty, J. Nucl. Mater. 151, 334 (1988).

24. B.J. Jaques, B.M. Marx, A.S. Hamdy, and D.P. Butt, J. Nucl. Mater. 381, 309 (2008).

25. N.R. Brown, A. Aronson, M. Todosow, R. Brito, and K.J. McClellan, Nucl. Eng. Des. 275, 393 (2014).

26. G. Zhang, M. Fratoni, and E. Greenspan, Ann. Nucl. Eng. 112,383 (2018)

27. V.I. Vybyvanets, M.L. Taubin, E.S. Solntseva, I.E. Galev, V.G. Baranov, A.V. Tenishev, and O.V. Khomyakov, Atom. Energ. 117 (4) (2015).

28. E.S. Solntceva, M.L. Taubin, V.I. Vybyvanets, I.E. Galov, V.G. Baranov, O.V. Homyakov, and A.V. Tenishev, Ann. Nucl. Energ. 87, 799 (2016).

29. S.L. Hayes, J.K. Thomas, and K.L. Peddicord, J. Nucl. Mater 171, 271 (1990).
30. V.I. Surin, N.A. Evstyuhin, and V.I. Cheburkov, J. Nucl. Mater. 218, 268 (1995).

31. K. Tanaka, K. Maeda, K. Katsuyama, M. Inoue, T. Iwai, and Y. Arai, J. Nucl. Mater. 327, 77 (2004).

32. S.B. Ross and M.S. El-Genk, J. Nucl. Mater. 170, 169 (1990).

33. H. Blank, K. Richter, M. Coquerelle, H. Matzke, M. Campana, C. Sari, and I.L.F. Ray, J. Nucl. Mater. 166, 95 (1989).

34. S.S. Parker, J.T. White, P. Hosemann, and A.T. Nelson, 526 (2019).

35. X. Ding, T. Kaneshiki, M. Arima, M. Nomura, T. Suzuki, and Y. Fujii, Prog. Nucl. Energy 50 (2), 504 (2008).

36. R.G. Sanchez, D.J. Loaiza, R.H. Kimpland, D.K. Hayes, C.C. Cappiello, M.L. Myers, P.J. Jaegers, S.D. Clement, and K.B. Butterfield, ICNC2003: 7. International Conference on $\mathrm{Nu}$ clear Criticality Safety. Challenges in the Pursuit of Global Nuclear Criticality Safety, Tokai, Ibaraki, Japan, 20-24 Oct 2003. JAERI-Conf-2003-019-PT1 (Japan Atomic Energy Research Inst., Kashiwa, Chiba, Japan, 2003), pp. 201-203. https://inis.iaea.org/search/search.aspx?orig_q=RN:3611645 3 .

37. E.N. Avrorin and A.N. Chebeskov, Nucl. Energy Technol. 1 (1), 1 (2015)

38. D.R. Smith and W.U. Geer, Nucl. Appl. Technol. 7 (5), 405 (1969).

39. J.J. Vandenkieboom, Nuclear Nonproliferation Workshop, DOE/HQ, Washington, DC, LA-UR-11-03126 (2011).

40. R.S. Herbst, P. Baron, and M. Nilsson, Woodhead Publishing Series in Energy (2011), pp. 141-175.

41. Y. Kimura, M. Saito, H. Sagara, and C.H. Yan, Ann. Nucl. Energy 46 (1), 152 (2012).

42. S. Sahin and J. Ligou, Nucl. Technol. 50 (1), 88 (2017).

43. D.A.P. Palma and M.S. Rocha, J. Power Energy Eng. 8 (6), 1054 (2014).

Publisher's Note Springer Nature remains neutral with regard to jurisdictional claims in published maps and institutional affiliations. 